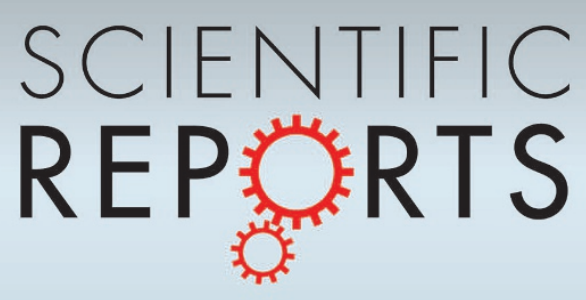

OPEN

SUBJECT AREAS:

PHOTOCATALYSIS

SYNTHESIS AND PROCESSING

Received

11 November 2014

Accepted

5 March 2015

Published

31 March 2015

Correspondence and requests for materials should be addressed to

T.H. (het@nanoctr.cn) or Y.C. (caoya@ nankai.edu.cn)

\section{Efficient visible-light photocatalytic degradation system assisted by conventional Pd catalysis}

\author{
Yanlong Yu', Tao He², Lingju Guo², Yajun Yang' ', Limei Guo', Yue Tang' \& Yaan Cao'
}

\begin{abstract}
'Key laboratory of Weak-Light Nonlinear Photonics, Ministry of Education, TEDA Applied Physics Institute and School of Physics, Nankai University, Tianjin 300457, China, ${ }^{2}$ Laboratory of Nanosystem and Hierarchical Fabrication, National Center for Nanoscience and Technology, Beijing 100190, China.
\end{abstract}

Different approaches like doping and sensitization have been used to develop photocatalysts that can lead to high reactivity under visible-light illumination, which would allow efficient utilization of solar irradiation and even interior lighting. We demonstrated a conceptually different approach by changing reaction route via introducing the idea of conventional Pd catalysis used in cross-coupling reactions into photocatalysis. The -O-Pd-Cl surface species modified on $\mathrm{Ni}$-doped $\mathrm{TiO}_{2}$ can play a role the same as that in chemical catalysis, resulting in remarkably enhanced photocatalytic activity under visible-light irradiation. For instance, $\mathrm{Pd} / \mathrm{Ni}-\mathrm{TiO}_{2}$ has much higher activity than $\mathrm{N}-\mathrm{TiO}_{2}$ (about $3 \sim 9$ times for all of the 4-XP systems) upon irradiation with wavelength of $420 \mathrm{~nm}$. The catalytically active $\operatorname{Pd}(0)$ is achieved by reduction of photogenerated electrons from $\mathrm{Ni}_{-} \mathrm{TiO}_{2}$. Given high efficient, stable Pd catalysts or other suitable chemical catalysts, this concept may enable realization of the practical applications of photocatalysis.

$\mathrm{n}$ heterogeneous photocatalysis, the organic pollutants can be degraded via direct oxidization by the oxidative species generated upon photoexcitation of a photocatalyst. Many photocatalysts have been designed and prepared to achieve this. $\mathrm{TiO}_{2}$ is the most widely studied one due to its nontoxicity and high photostability ${ }^{1,2}$. However, so far the photocatalytic efficiency for all of these catalysts is still low, which keeps them far away from practical applications. It is noted that the efficiency of such a photocatalytic system (PCS) can be improved by controllable modulation of light harvest and behavior of photogenerated charge carriers, which can be realized by different design concepts, such as modulation of crystallographic facets and morphology, doping, sensitization, surface treatment, and combination with other semiconductors and noble metals ${ }^{3-18}$. The majority of these studies are focused on the modification of the photocatalysts themselves. However, the photodegration efficiency is still not high enough hitherto, especially for those under visible-light irradiation that accounts for about $44 \%$ of total solar energy. On the other hand, the efficiency can also be improved if the photodegradation route of pollutants can be changed beforehand. A different concept for the design of a PCS can be proposed accordingly.

It is known that the reaction rate can be promoted remarkably by a catalyst via changing the reaction route in a chemical reaction, as less free energy is required to reach the transition state (i.e., intermediate). Coupling reaction is one of the most famous catalytic chemical reactions, for which palladium $(\mathrm{Pd})$ catalysts are often used ${ }^{19-22}$. The tetrakis(triphenylphosphine) palladium(0) is the common catalyst for homogeneous catalytic reaction, and in heterogeneous Pd catalysis, Pd is often fixed to a solid support in the form of dopant, particle, and $\operatorname{complex}^{20,21}$. Besides the coupling reactions, Pd catalysts can also be used in hydrogenation reaction ${ }^{23}$, hydrogen evolution ${ }^{24}$, and NO reduction ${ }^{25}$. Although the Pd species have been employed to improve the photocatalytic degradation too, the mechanism is different from the above Pd catalysis, for which the Pd species can act as the center for electron collection $^{26}$, change active sites at the (grain) interface of two solids ${ }^{27}$, or absorb light due to surface plasma resonance effect ${ }^{28}$.

In this work, the concept of conventional Pd catalysis used in the cross-coupling reactions is thus introduced into the PCS so as to efficiently photodegrade the organic pollutant. The target molecules are the toxic 4halogeno-phenol $\left(\mathrm{X}_{-} \mathrm{C}_{6} \mathrm{H}_{4}-\mathrm{OH}\right.$, denoted as $4-\mathrm{XP}, \mathrm{X}=\mathrm{F}, \mathrm{Cl}, \mathrm{Br}$, and I, respectively), as it exhibits similarity in molecular structure to those used in cross-coupling reactions and is very difficult to be removed from the contaminated water. The Pd catalyst is the $-\mathrm{O}-\mathrm{Pd}-\mathrm{Cl}$ surface species modified on $\mathrm{Ni}$-doped $\mathrm{TiO}_{2}$. The obtained PCS shows greatly enhanced photodegradation of 4-XP under visible-light irradiation, implying the feasibility of this novel design concept for efficient photocatalysis. 


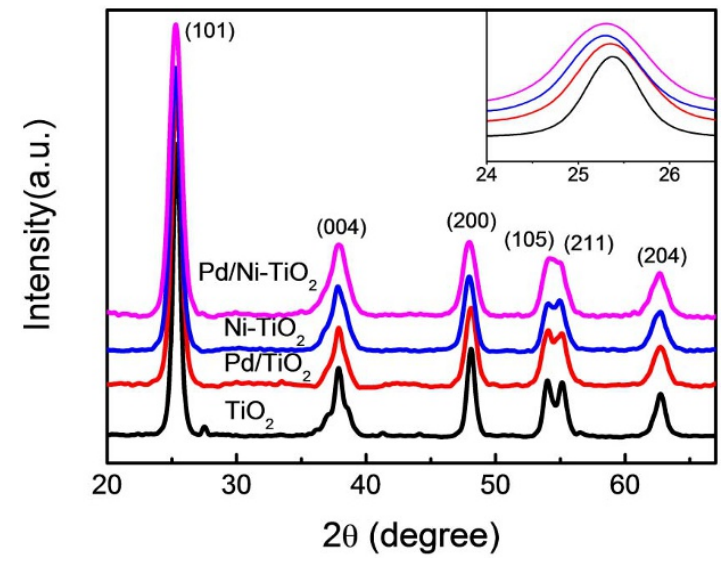

Figure $1 \mid$ XRD patterns of different as-prepared photocatalysts. Inset is the enlarged XRD peaks of crystal plane (101).

\section{Results}

Structure and composition of as-prepared photocatalysts. The $\mathrm{TiO}_{2}$-based photocatalysts modified by Pd surface species are used in this work, which are prepared by a sol-gel method. Only anatase $\mathrm{TiO}_{2}$ can be observed in the XRD patterns for all of the photocatalysts (Fig. 1), indicating that no phase change among different samples. Moreover, no patterns ascribed to the oxides of $\mathrm{Pd}$ or $\mathrm{Ni}$ can be observed. The cell volume and lattice parameters can be derived from the diffraction peaks corresponding to crystal planes (101) and (200) in the XRD patterns using Scherrer's formula, for which of $\mathrm{Ni}-\mathrm{TiO}_{2}$ are larger than those of pure $\mathrm{TiO}_{2}$ (Table 1). So Ni ions are doped in substitution mode as the ionic radius of $\mathrm{Ni}^{2+}(72 \mathrm{pm})$ is slightly larger than that of $\mathrm{Ti}^{4+}$ ions $(68 \mathrm{pm})$. While the cell volume and lattice parameters remain almost unchanged upon $\mathrm{Pd}$ modification (i.e., almost no shift in XRD peak), implying that $\mathrm{Pd}$ ions are not present in substitution or interstitial mode since the ionic radius of $\mathrm{Pd}^{2+}(86 \mathrm{pm})$ is much larger than that of $\mathrm{Ti}^{4+}$ ions. This is further confirmed by the high-resolution TEM results (see Supplementary Fig. S1). The fringe spacing (d) of (101) crystallographic plane is determined to be $3.52 \AA$ for both $\mathrm{TiO}_{2}$ and $\mathrm{Pd} / \mathrm{TiO}_{2}$, indicating that the modified $\mathrm{Pd}$ exists as surface species; while it increases to $3.59 \AA$ for $\mathrm{Pd} / \mathrm{Ni}-\mathrm{TiO}_{2}$, suggesting that $\mathrm{Ni}$ is doped into the crystal lattice as the ionic radius of $\mathrm{Ni}^{2+}$ is larger than that of $\mathrm{Ti}^{4+}$ ions. In addition, the BET specific surface area for $\mathrm{TiO}_{2}, \mathrm{Ni}-\mathrm{TiO}_{2}, \mathrm{Pd} / \mathrm{TiO}_{2}$, and $\mathrm{Pd} / \mathrm{Ni}-\mathrm{TiO}_{2}$ is determined to be $86.4,77.0,86.6$, and $90.3 \mathrm{~m}^{2} / \mathrm{g}$, respectively. That is to say, no big difference is found among different systems, which is consistent with the slight changes observed in the crystallite size (Table 1).

The chemical states of elements in different photocatalysts are determined by XPS technique. Since the radius of $\mathrm{Cl}^{-}$ions (182 $\mathrm{pm})$ is much larger than that of $\mathrm{O}_{2}{ }^{-}$ions $(140 \mathrm{pm})$, it is impossible for $\mathrm{Cl}^{-}$ions to be doped into $\mathrm{TiO}_{2}$ lattice in substitution or interstitial mode. The peak at $198.1 \mathrm{eV}$ for $\mathrm{TiO}_{2}$ sample is slightly lower than that of $\mathrm{Cl}_{2} \mathrm{p}_{3 / 2}$ in $\mathrm{TiCl}_{4}$ (Fig. $2 \mathrm{~A}$ ) ${ }^{29}$, which is ascribed to the $\mathrm{Cl}^{-}$ions linked with unsaturated $\mathrm{Ti}$ sites on the surface of $\mathrm{TiO}_{2}$, i.e., $-\mathrm{O}-\mathrm{Ti}-\mathrm{Cl}$

Table 1 | Cell parameters, cell volume and crystallite size of different samples derived from XRD data given in Figure 1

Cell parameters $/ \AA$

\begin{tabular}{lcccc}
\cline { 2 - 3 } Sample & $a=b$ & $c$ & Cell volume/ $\AA^{3}$ & Crystallite size/nm \\
\hline $\mathrm{TiO}_{2}$ & 3.7760 & 9.4039 & 134.08 & 14.2 \\
$\mathrm{Pd} / \mathrm{TiO}_{2}$ & 3.7786 & 9.3955 & 134.15 & 10.6 \\
$\mathrm{Ni}-\mathrm{TiO}_{2}$ & 3.7903 & 9.4704 & 136.06 & 9.8 \\
$\mathrm{Pd} / \mathrm{Ni}^{-} \mathrm{TiO}_{2}$ & 3.7890 & 9.4914 & 136.26 & 9.5
\end{tabular}

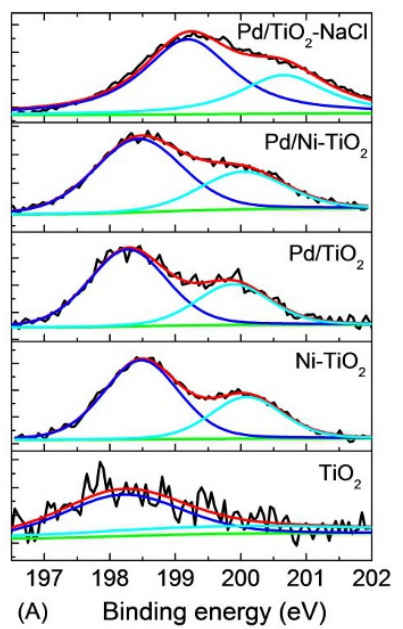

(B) Binding energy (eV)
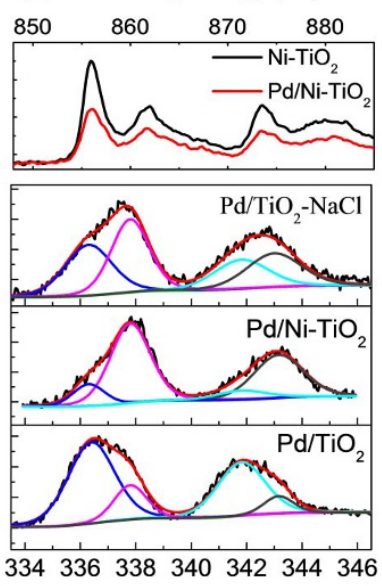

(C) Binding energy (eV)

Figure $2 \mid$ XPS spectra of different as-prepared photocatalysts. (A) Cl2p, (B) Ni2p and (C) Pd $3 \mathrm{~d}$.

structure $^{30,31}$. Our previous work demonstrates that this $-\mathrm{O}-\mathrm{Ti}-\mathrm{Cl}$ cannot cause visible-light response and can hardly influence photocatalytic activity under visible-light irradiation ${ }^{31}$. For the Cl2p XPS spectra of $\mathrm{Ni}-\mathrm{TiO}_{2}, \mathrm{Pd} / \mathrm{TiO}_{2}$ and $\mathrm{Pd} / \mathrm{Ni}-\mathrm{TiO}_{2}$ samples, the binding energy $(\mathrm{BE})$ of $\mathrm{Cl} 2 \mathrm{p}_{3 / 2}$ peaks $(198.3-198.5 \mathrm{eV})$ locates between that of $\mathrm{TiCl}_{4}(198.2 \mathrm{eV})$ and $\mathrm{NiCl}_{2}(199.2 \mathrm{eV})$ or $\mathrm{PdCl}_{2}(198.9 \mathrm{eV})$ (Fig. 2A). Hence, the $\mathrm{Cl}^{-}$ions are linked with unsaturated Ti or other metal sites on the surface (i.e., $-\mathrm{O}-\mathrm{Me}-\mathrm{Cl}$ structure, $\mathrm{Me}=\mathrm{Ti}, \mathrm{Ni}$, and $\mathrm{Pd})$. The amount of such surface species increases greatly when $\mathrm{TiO}_{2}$ is modified by Ni and/or Pd, as the XPS signal increases significantly upon the modification.

For both $\mathrm{Ni}-\mathrm{TiO}_{2}$ and $\mathrm{Pd} / \mathrm{Ni}-\mathrm{TiO}_{2}$ samples, two pairs of doublet $\mathrm{Ni} 2 \mathrm{p}$ peaks as well as the corresponding satellite peaks (around 862 and $880 \mathrm{eV}$ ) can be observed in the spectra (Fig. 2B). The peak located at around $855.8 \mathrm{eV}$ for $\mathrm{Ni} 2 \mathrm{p}_{3 / 2}$ is attributed to the doped $\mathrm{Ni}$ ions in $\mathrm{TiO}_{2}$ lattice, since the peak position is almost the same as -Ti-O-Ni-O- structure in the bulk $\mathrm{NiTiO}_{3}(855.9 \mathrm{eV})^{32}$. Considering the above $\mathrm{Cl} 2 \mathrm{p}$ XPS results, another one at around $856.7 \mathrm{eV}$ is ascribed to the surface $-\mathrm{O}-\mathrm{Ni}-\mathrm{Cl}$ structure. Moreover, it seems that the total amount of $\mathrm{Ni}$ species in the catalyst decreases in the $\mathrm{Pd} / \mathrm{Ni}-\mathrm{TiO}_{2}$ compared with that in $\mathrm{Ni}-\mathrm{TiO}_{2}$, as the XPS signal decreases obviously for $\mathrm{Pd} / \mathrm{Ni}-\mathrm{TiO}_{2}$.

Two pairs of doublet Pd3d peaks can be observed in the spectra for both $\mathrm{Pd} / \mathrm{TiO}_{2}$ and $\mathrm{Pd} / \mathrm{Ni}-\mathrm{TiO}_{2}$ samples (Fig. 2C). The peak at $336.2 \mathrm{eV}$ for $\mathrm{Pd} 3 \mathrm{~d}_{5 / 2}$ is ascribed to $-\mathrm{O}-\mathrm{Pd}-\mathrm{O}-$ structure at the surface (i.e., one $\mathrm{Pd}^{2+}$ ion is linked with two unsaturated oxygen ions). Considering the aforementioned $\mathrm{Cl} 2 \mathrm{p}$ XPS results as well as the BE of $\mathrm{Pd} 3 \mathrm{~d}_{5 / 2}$ for $\mathrm{PdO}(336.3 \mathrm{eV})$ and $\mathrm{PdCl}_{2}(337.9 \mathrm{eV})$, another $\mathrm{Pd} 3 \mathrm{~d}_{5 / 2}$ peak at $337.7 \mathrm{eV}$ is attributed to $-\mathrm{O}-\mathrm{Pd}-\mathrm{Cl}$ structure (i.e., one $\mathrm{Pd}^{2+}$ ion is linked with one $\mathrm{Cl}^{-}$ion and one unsaturated oxygen ion) at the surface. Furthermore, the ratio of -O-Pd-Cl structure to-O-Pd-Ois much higher for $\mathrm{Pd} / \mathrm{Ni}-\mathrm{TiO}_{2}$ than $\mathrm{Pd} / \mathrm{TiO}_{2}$, implying that the major surface species is $-\mathrm{O}-\mathrm{Pd}-\mathrm{Cl}$ for $\mathrm{Pd} / \mathrm{Ni}-\mathrm{TiO}_{2}$ while $-\mathrm{O}-\mathrm{Pd}-$ $\mathrm{O}-$ for $\mathrm{Pd} / \mathrm{TiO}_{2}$. Since the total amount of $\mathrm{Ni}$ species in $\mathrm{Pd} / \mathrm{Ni}-\mathrm{TiO}_{2}$ catalyst is less than that in $\mathrm{Ni}-\mathrm{TiO}_{2}$, the utilization of $\mathrm{Ni}$ species during catalyst synthesis may promote the formation of surface $-\mathrm{O}-\mathrm{Pd}-\mathrm{Cl}$ species, possibly because the structure containing $\mathrm{Ni}^{2+}$ ions can change into $-\mathrm{O}-\mathrm{Pd}-\mathrm{Cl}$ in the presence of $\mathrm{Pd}^{2+}$ ions. So the synergistic interactions are present between $\mathrm{Pd}$ and $\mathrm{Ni}$ species to some degree during the catalyst synthesis.

In addition, $\mathrm{NaCl}$, instead of $\mathrm{NiCl}_{2}$, has been used during the synthesis too, which can also provide $\mathrm{Cl}^{-}$ions. The XPS signal of -O-Pd-Cl structure can be observed too. Moreover, the ratio of -O$\mathrm{Pd}-\mathrm{Cl}$ structure to $-\mathrm{O}-\mathrm{Pd}-\mathrm{O}-$ for the $\mathrm{Pd} / \mathrm{TiO}_{2}-\mathrm{NaCl}$ catalyst is still 

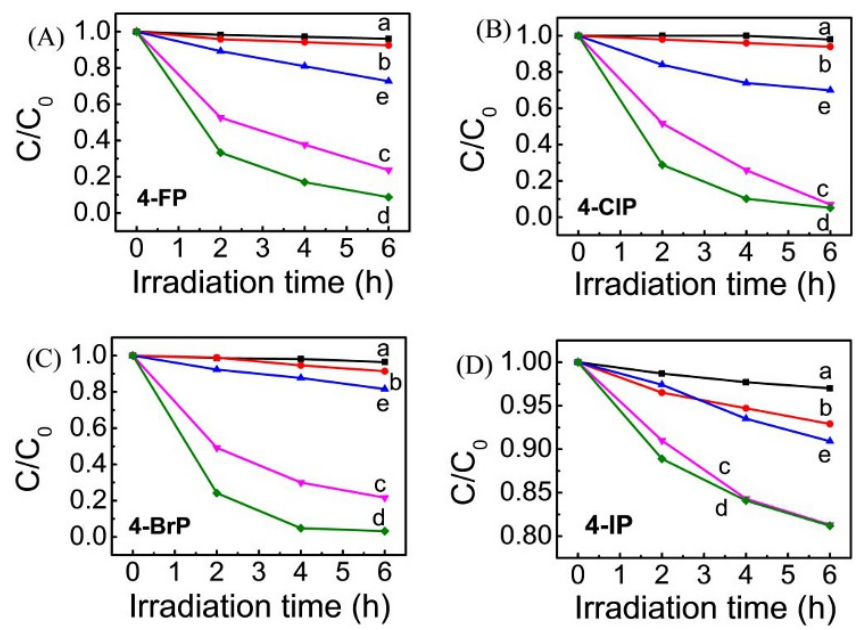

Figure $3 \mid$ Photodegradation of different target molecules under visiblelight irradiation $(\lambda>420 \mathrm{~nm})$ in aqueous suspension with $10 \mathrm{mg}$ of photocatalyst. (a) pure $\mathrm{TiO}_{2}$, (b) $\mathrm{Ni}-\mathrm{TiO}_{2}$, (c) $\mathrm{Pd} / \mathrm{TiO}_{2}$, (d) $\mathrm{Pd} / \mathrm{Ni}-\mathrm{TiO}_{2}$ and (e) $\mathrm{N}-\mathrm{TiO}_{2}$.

larger than that for the $\mathrm{Pd} / \mathrm{TiO}_{2}$, while it is smaller than that for $\mathrm{Pd} /$ $\mathrm{Ni}-\mathrm{TiO}_{2}$ (Fig. 2C). This implies that the presence of $\mathrm{Cl}^{-}$ions during the catalyst synthesis can be also in favor of the formation of surface $-\mathrm{O}-\mathrm{Pd}-\mathrm{Cl}$ species, especially via the conversion of $-\mathrm{O}-\mathrm{Pd}-\mathrm{O}-$ into $-\mathrm{O}-\mathrm{Pd}-\mathrm{Cl}$, though the contribution may be less than that from the $\mathrm{Ni}$ species.

Photocatalytic activity. Photodegradation of $\mathrm{X}-\mathrm{C}_{6} \mathrm{H}_{4}-\mathrm{OH}(4-\mathrm{XP}, \mathrm{X}$ $=\mathrm{F}, \mathrm{Cl}, \mathrm{Br}$, and $\mathrm{I}$, respectively), a hazardous and toxic pollutant, has been used as target molecules to evaluate the photocatalytic activity of the resultant PCS under visible-light irradiation. The nitrogen doped $\mathrm{TiO}_{2}\left(\mathrm{~N}-\mathrm{TiO}_{2}\right)$ is also given here for comparison, as it shows relatively good visible-light photocatalytic activity. The photocatalytic activity upon visible-light irradiation $(\lambda>420 \mathrm{~nm})$ falls in the series $\mathrm{TiO}_{2}<\mathrm{Ni}-\mathrm{TiO}_{2}<\mathrm{N}-\mathrm{TiO}_{2}<\mathrm{Pd} / \mathrm{TiO}_{2}<\mathrm{Pd} / \mathrm{Ni}-$ $\mathrm{TiO}_{2}$ for all of the systems (Fig. 3), especially in initial stage of the photodegradation. That is to say, $\mathrm{TiO}_{2}$ and $\mathrm{Ni}-\mathrm{TiO}_{2}$ exhibit very low activity; while $\mathrm{Pd} / \mathrm{TiO}_{2}$ shows a remarkably improved activity, and $\mathrm{Pd} / \mathrm{Ni}-\mathrm{TiO}_{2}$ has the highest activity. When compared $\mathrm{Pd} / \mathrm{Ni}-\mathrm{TiO}_{2}$ with $\mathrm{Pd} / \mathrm{TiO}_{2}$ for the photodegradation in the first two hours, the enhancement amplitude is about $40.7 \%, 47.5 \%, 49.1 \%$, and $23.3 \%$ for 4-FP, 4-ClP, 4-BrP, and 4-IP, respectively. Furthermore, $\mathrm{Pd} / \mathrm{Ni}-\mathrm{TiO}_{2}$ has much higher activity than $\mathrm{N}-\mathrm{TiO}_{2}$ (about $3 \sim 9$ times for all of the 4-XP systems), and is even much higher than $\mathrm{Ni}^{-} \mathrm{TiO}_{2}$ (about 15.3, 34.6, 67.9, and 2.2 times for 4-FP, 4-ClP, 4-BrP, and 4-IP, respectively). Thus, the presence of $\mathrm{Pd}$ species can greatly improve the visible-light photocatalytic activity of the reported PCS, while Ni species just improve it slightly. To further confirm this, in addition,

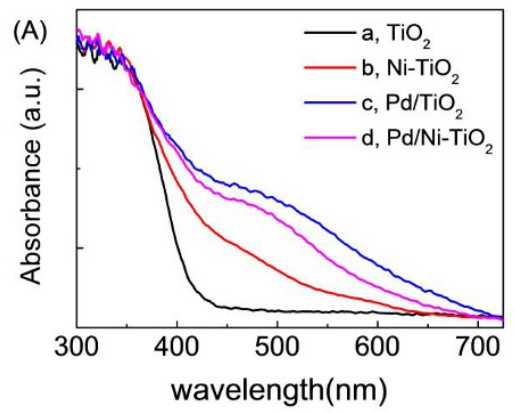

4-ClP has been photodegraded with less amount of photocatalyst ( $5 \mathrm{mg}$, instead of $10 \mathrm{mg}$ in the above experiments) under illumination with slightly higher energy $(\lambda>400 \mathrm{~nm})$. Exactly the same trend is observed (see Supplementary Fig. S2).

Since no big difference in the BET specific surface area is found among $\mathrm{TiO}_{2}, \mathrm{Ni}-\mathrm{TiO}_{2}, \mathrm{Pd} / \mathrm{TiO}_{2}$, and $\mathrm{Pd} / \mathrm{Ni}-\mathrm{TiO}_{2}$, the effect of surface area on the photocatalytic activity can be ignored here. It is noted that the photocatalytic activity of a PCS is closely related to its optoelectronic properties. Pure $\mathrm{TiO}_{2}$ shows no visible-light absorption due to its large band gap of $3.1 \mathrm{eV}$, while the other three have relatively strong absorption in the visible-light region due to the formation of $\mathrm{Ni}$ doping energy levels and/or $-\mathrm{O}-\mathrm{Me}-\mathrm{Cl}$ surface species (Fig. 4A). It is noted that $\mathrm{Pd} / \mathrm{TiO}_{2}$ has the strongest visible-light absorption, followed by $\mathrm{Pd} / \mathrm{Ni}-\mathrm{TiO}_{2}$. As discussed above, the major surface species is $-\mathrm{O}-\mathrm{Pd}-\mathrm{Cl}$ for $\mathrm{Pd} / \mathrm{Ni}-\mathrm{TiO}_{2}$ owing to the facilitated formation of $-\mathrm{O}-\mathrm{Pd}-\mathrm{Cl}$ by the presence of $\mathrm{Ni}$ species during catalyst synthesis, while it is $-\mathrm{O}-\mathrm{Pd}-\mathrm{O}-$ for $\mathrm{Pd} / \mathrm{TiO}_{2}$. It is believed that $-\mathrm{O}-\mathrm{Pd}-\mathrm{O}-$ exhibits stronger visible-light absorption than $-\mathrm{O}-\mathrm{Pd}-\mathrm{Cl}$ and $-\mathrm{O}-\mathrm{Ni}-\mathrm{Cl}$. This may explain why the $\mathrm{Pd} / \mathrm{TiO}_{2}$ shows stronger visible-light absorption than $\mathrm{Pd} / \mathrm{Ni}-\mathrm{TiO}_{2}$.

Furthermore, the $\mathrm{Pd} / \mathrm{TiO}_{2}$ exhibits higher visible-light surface photovoltaic spectroscopic (SPS) response throughout $400 \sim$ $600 \mathrm{~nm}$ than $\mathrm{Pd} / \mathrm{Ni}-\mathrm{TiO}_{2}$, although both of them are relatively low (Fig. 4B). $\mathrm{Ni}^{-\mathrm{TiO}_{2}}$ exhibits very little visible-light SPS response (only a small bump around $400 \sim 430 \mathrm{~nm}$ ) and no visible-light SPS response at all for $\mathrm{TiO}_{2}$. Such a SPS response corresponds to the visiblelight phtotocatalysis, i.e., only a PCS exhibits SPS response that can show photocatalysis, though maybe with different activity due to the influences from other factors. Besides the above photodegradation results, indeed, about $28.6 \%$ of 4 - $\mathrm{ClP}$ are photodegraded for $\mathrm{Pd} / \mathrm{TiO}_{2}$ and $33.3 \%$ for $\mathrm{Pd} / \mathrm{Ni}-\mathrm{TiO}_{2}$ under irradiation with a wavelength longer than $450 \mathrm{~nm}$ for $8 \mathrm{~h}$, while no photodegradation is observed for $\mathrm{Ni}-\mathrm{TiO}_{2}$. Then, the question arises. Why the PCS with $\mathrm{Pd} / \mathrm{Ni}-\mathrm{TiO}_{2}$ shows lower visible-light absorption and SPS response than $\mathrm{Pd} / \mathrm{TiO}_{2}$, but has higher photocatalytic activity?

\section{Discussion}

It is noted that the formation of some intermediates (such as hydroxyphenyl radicals) upon photoexcitation from the 4-XP molecules adsorbed on the photocatalyst surface is the first and critical step in the photodegradation, which will further undergo a sequence of reactions, eventually leading to a complete photodegradation of 4$\mathrm{XP}$ into $\mathrm{CO}_{2}$ and $\mathrm{H}_{2} \mathrm{O}^{33,34}$. Thus, the photocatalytic efficiency can be improved significantly if the high free energy required for this critical process can be reduced via chemical catalysis. Considering the formation of a stable trans- $\sigma-\mathrm{Pd}(\mathrm{II})$ intermediate via reduction of a $\operatorname{Pd}(0)$ complex catalyst is the key step in the cross-coupling reactions ${ }^{20-22}$, it is suggested that the -O-Pd-Cl surface species reported here can play a similar role, i.e., acting as the catalyst too (actually $-\mathrm{O} \rightarrow \mathrm{Pd}(0) \leftarrow \mathrm{Cl})$. The catalytically active $\mathrm{Pd}(0)$ complex is formed in-situ in the cross-coupling reactions, typically through oxidation of

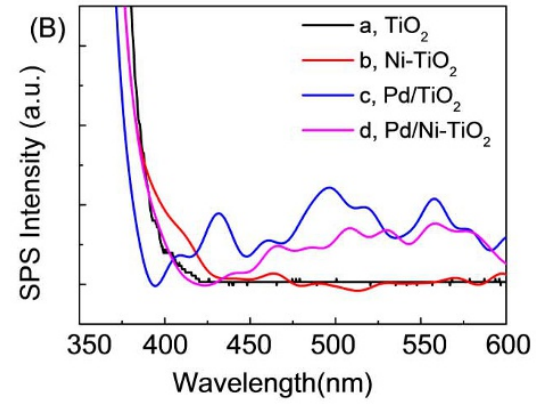

Figure $4 \mid$ Optoelectronic properties of the as-prepared photocatalysts. (A) UV-vis absorption spectra and (B) surface photovoltaic spectra (SPS). (a) $\mathrm{TiO}_{2}$, (b) $\mathrm{Ni}-\mathrm{TiO}_{2}$, (c) $\mathrm{Pd} / \mathrm{TiO}_{2}$ and (d) $\mathrm{Pd} / \mathrm{Ni}-\mathrm{TiO}_{2}$. 


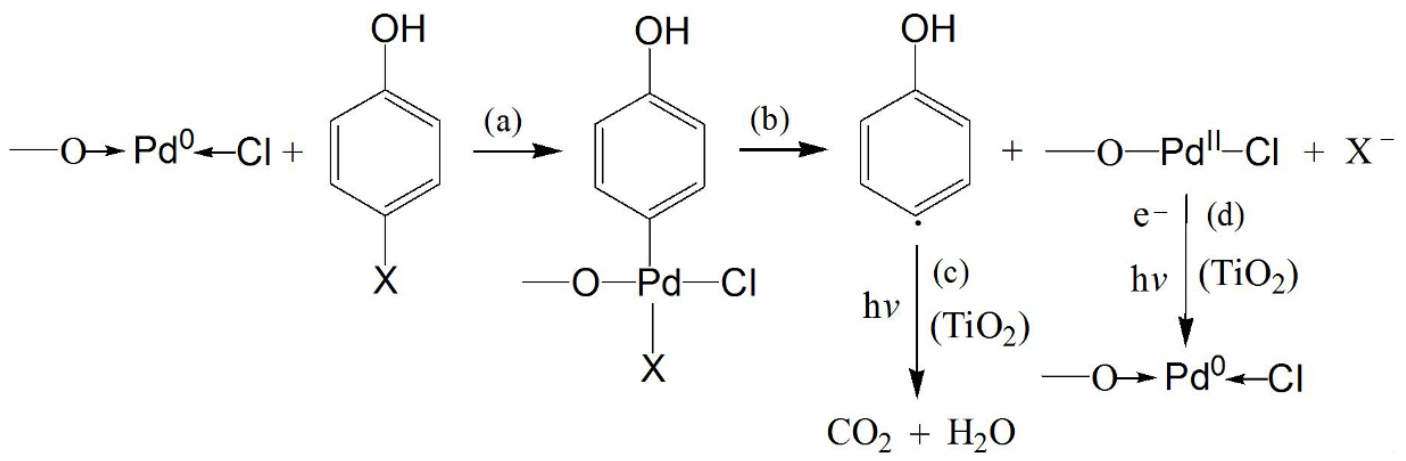

Figure $5 \mid$ Photocatalytic degradation mechanism upon visible-light irradiation. $\mathrm{X}=\mathrm{F}, \mathrm{Cl}, \mathrm{Br}$, and $\mathrm{I}$.

a reductant like phosphine ligand if a $\mathrm{Pd}(\mathrm{II})$ catalyst is used initially. Since no such reducing agent is present in our PCS, it is suggested that here the active $-\mathrm{O} \rightarrow \mathrm{Pd}(0) \leftarrow \mathrm{Cl}$ is formed via the reduction of $-\mathrm{O}-\mathrm{Pd}(\mathrm{II})-\mathrm{Cl}$ by photogenerated electrons upon irradiation, which can react with the target molecules to form organopalladium intermediates that can further produce the short-lived hydroxyphenyl radicals (HPR) via reaction with the photogenerated electrons and/ or holes (Fig. 5). The degradation occurring thereafter is similar to those in conventional photocatalysis. It is believed that the conventional photodegradation mechanism plays a trivial role in this initial stage, even if it does play a role.

The formation of HPR has been confirmed previously ${ }^{35}$, which will undergo further rapid oxidation to the final mineralization products carbon dioxide and water. The regeneration of $-\mathrm{O}-\mathrm{Pd}(\mathrm{II})-\mathrm{Cl}$ from the active $-\mathrm{O} \rightarrow \mathrm{Pd}(0) \leftarrow \mathrm{Cl}$ can be realized by the oxidization of oxygen or holes, though it is noted that the amount of -O-Pd(II)$\mathrm{Cl}$ decreases to some degree according to the signal intensity of $\mathrm{Cl} 2 \mathrm{p}$ XPS (see Supplementary Fig. S3). Except the 4-IP system, the relative reactivity in terms of photodegradation decreases in the order of $\mathrm{Br}$ $>\mathrm{Cl}>\mathrm{F}$, which is the same as that for the cross-coupling reactions. Moreover, in a moderate range, the photocatalytic activity increases with the increasing amount of $\mathrm{Pd}$ and $\mathrm{Ni}$ introduced during catalyst synthesis (see Supplementary Fig. S4), due to the increased amount of $-\mathrm{O}-\mathrm{Pd}-\mathrm{Cl}$; while the activity decreases when the amount of $\mathrm{Ni}$ is too high, possibly because the surface $\mathrm{Ni}$ species can also act as recombination centers. Thus, the proposed concept is successfully realized, which may afford a feasible approach for design of an efficient PCS, even in the case of inferior visible-light absorption because the critical step for formation of the degradable intermediates is via Pd catalysis instead of via direct interactions with the photogenerated electrons or holes. This mechanism can also explain why the $\mathrm{TiO}_{2}$ modified by $\mathrm{Ni}$ and/or Pd has shorter photoluminescence lifetime than $\mathrm{TiO}_{2}$ (see Supplementary Fig. S5), while exhibits higher visiblelight photodegradation activity on 4 -XP as discussed above.

As for the 4-IP system, similar to that for the cross-coupling reactions, it is believed that the $-\mathrm{O}-\mathrm{Pd}(\mathrm{II})-\mathrm{Cl}$ may still exhibit very high catalytic activity for the formation of organopalladium intermediate and short-lived HPR, possibly higher than that for the 4-BrP too. Unlike the cross-coupling reactions, however, some of the resultant $\mathrm{HPR}$ can react with each other to form a dimer or other oligomer due to the absence of other reactants in the system for addition reactions with these intermediates. These oligomers are more difficult to be photodegraded than the corresponding monomer. Although no suitable facilities are available to probe the resultant intermediates or oligomers, this speculation can be proved indirectly by the UV-vis absorption spectra after irradiation (see Supplementary Fig. S6). The absorption corresponding to the benzene ring $(\sim 230 \mathrm{~nm})$ decreases with increasing irradiation time. Meanwhile a new absorption bump appears at around $255 \mathrm{~nm}$, corresponding to the absorption of oligomers. For the 4-IP system, the intensity of this new absorption reaches a maximum value in a relatively short time $(2-3 \mathrm{~h})$, while it keeps increasing with irradiation time for the 4-BrP system. This may suggest the rapid formation of oligomers for the 4-IP PCS due to high catalytic effect on the 4-IP system, resulting in the abnormal low photodegradation of 4 -IP.

Here both the $-\mathrm{O}-\mathrm{Pd}(\mathrm{II})-\mathrm{O}-$ and $-\mathrm{O}-\mathrm{Ni}(\mathrm{II})-\mathrm{Cl}$ species cannot play such a role, or very little even if they could. For the former, it may be because it is difficult to form the organopalladium intermediate or HPR, possibly because both the oxygen ions linked to the Pd atom are also connected with another ion. Furthermore, PdO shows very low activity for the photocatalytic degradation of 4-XP (see Supplementary Fig. S7). On the other hand, no PdO is observed from the $\mathrm{XRD}$ patterns. For the $-\mathrm{O}-\mathrm{Ni}(\mathrm{II})-\mathrm{Cl}$, it is possibly because it cannot be reduced efficiently by photogenerated electrons. Or, even if organonickel intermediate could be formed, calculation results indicate that the dissociation energy of $\mathrm{Ni}-\mathrm{X}$ in the corresponding intermediate is larger than that of Pd-X (see Supplementary Table S1). So the X atom linked to the Pd atom can be more easily dropped out than that linked to $\mathrm{Ni}$. So the $-\mathrm{O}-\mathrm{Ni}$ (II)-Cl would not be an efficient catalyst in the 4-XP degradation, even it could act as a chemical catalyst. In addition, although no direct evidence shows the existence of the active $-\mathrm{O} \rightarrow \mathrm{Pd}(0) \leftarrow \mathrm{Cl}$ intermediate under visible-light irradiation, the signal of $\operatorname{Pd}(0)$ can be observed in the XPS spectrum $(\sim 334.5 \mathrm{eV}$ for Pd3d5/2) after UV-light photodegradation of target molecules when the same photocatalysts are used (see Supplementary Fig. S8). This may also imply the viability of the proposed mechanism.

Moreover, as discussed above, the presence of $\mathrm{Cl}^{-}$ions during the catalyst synthesis can be in favor of the formation of surface -O-Pd$\mathrm{Cl}$ species, especially via the conversion of $-\mathrm{O}-\mathrm{Pd}-\mathrm{O}-$ into $-\mathrm{O}-\mathrm{Pd}-$ $\mathrm{Cl}$. Thus, the photocatalysts have also been prepared with the same protocol but without the presence of $\mathrm{Cl}$ species in the starting materials so as to further study the effect of $\mathrm{Cl}^{-}$ions. It is found that all the obtained photocatalysts still exhibit visible-light response (see Supplementary Fig. S9). Similar to the catalysts prepared with the presence of $\mathrm{Cl}$ species, $\mathrm{Pd} / \mathrm{TiO}_{2}$ has the strongest visible-light absorption, followed by $\mathrm{Pd} / \mathrm{Ni}-\mathrm{TiO}_{2}$, and $\mathrm{Ni}-\mathrm{TiO}_{2}$ is the weakest. It can be seen from Figure 6 that the photodegradation activity of the obtained catalysts is much lower than the catalysts prepared with the presence of $\mathrm{Cl}$ species (Fig. 3b). For instance, the obtained $\mathrm{Ni}^{-} \mathrm{TiO}_{2}$ shows almost no activity on 4-ClP photodegradation. When the same amount of $\mathrm{Pd}$ is used in the precursor (1.5\%), only about $35 \%$ of 4-ClP is decomposed after 4 hours of photodegradation for the catalyst prepared without $\mathrm{Cl}\left(1.5 \mathrm{Pd} / \mathrm{Ni}-\mathrm{TiO}_{2}\right)$; while almost all of the 4 $\mathrm{ClP}$ is decomposed after 4 hours for the catalyst prepared with $\mathrm{Cl}$ (Fig. 3b). The same is true for the $\mathrm{Pd} / \mathrm{TiO}_{2}$ catalyst. Therefore, the presence of $\mathrm{Cl}$ species in the precursor is very important. These results can further confirm the feasibility of the proposed mechanism.

\section{Conclusion}

In summary, we have demonstrated a new design concept for efficient visible-light photocatalysis, i.e., a conventional Pd catalysis 


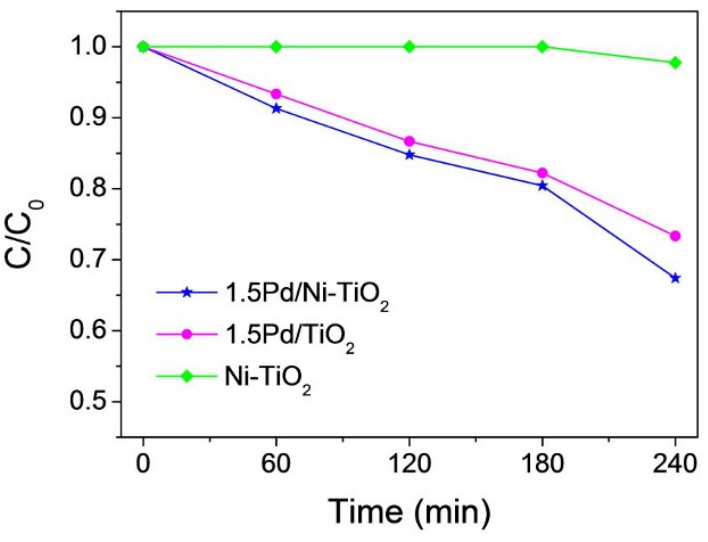

Figure 6 Photodegradation of 4-ClP under visible-light irradiation $(\lambda>420 \mathrm{~nm})$ in aqueous suspension with $10 \mathrm{mg}$ of different photocatalysts prepared without the presence of $\mathrm{Cl}$ species in the starting materials.

used in the coupling reactions is introduced into the PCS so as to change the photodegradation route of the pollutants. The results show that the Pd surface species modified on the Ni-doped $\mathrm{TiO}_{2}$ can act as the $\mathrm{Pd}$ catalyst. The catalytically active $\operatorname{Pd}(0)$ is achieved by reduction of photogenerated electrons from $\mathrm{Ni}-\mathrm{TiO}_{2}$. The resultant PCS exhibits remarkably improved efficient photodegradation of 4-XP under visible-light irradiation. Stability, activity, selectivity and versatility of such Pd complex catalysts are open to the systematic study for developing suitable PCS so as to enable realization of the practical applications of photocatalysis. The Pd may be replaced by $\mathrm{Ni}, \mathrm{Fe}$ or $\mathrm{Cu}$ in a specific system. We envision that the future investigations may even develop a PCS that can work efficiently in the case of inferior visible-light absorption, as the critical step for formation of the intermediates is via Pd catalysis instead of via direct interactions with the photogenerated electrons or holes. We believe that not only the field of photocatalytic degradation, but also other photocatalytic fields like photosynthesis may be benefited from this too since it is developed from coupling reactions.

\section{Methods}

Chemicals. All chemicals used were of analytical grade and the water was deionized water $(>18.2 \mathrm{M} \Omega \cdot \mathrm{cm})$. At room temperature, certain volume of $\mathrm{NiCl}_{2}(0.5 \mathrm{~mol} / \mathrm{L})$ and $\mathrm{PdCl}_{2}(0.1169 \mathrm{~mol} / \mathrm{L})$ solution were mixed with $40 \mathrm{~mL}$ of ethanol. Then $1 \mathrm{~mL}$ of $\mathrm{HCl}$ solution $(12 \mathrm{~mol} / \mathrm{L})$ and $12 \mathrm{~mL}$ of $\mathrm{Ti}\left(\mathrm{OC}_{4} \mathrm{H}_{9}\right)_{4}$ was added dropwise into the mixture under vigorous stirring. The mixture was stirred until the formation of $\mathrm{TiO}_{2}$ gel, followed by being aged for $24 \mathrm{~h}$. The obtained gels were dried at $373 \mathrm{~K}$ for $10 \mathrm{~h}$ and annealed at $723 \mathrm{~K}$ in a muffle for $2.5 \mathrm{~h}$. The resultant samples were denoted as $\mathrm{Pd} / \mathrm{Ni}-\mathrm{TiO}_{2}$. Pure $\mathrm{TiO}_{2}, \mathrm{Ni}$ doped $\mathrm{TiO}_{2}\left(\mathrm{Ni}-\mathrm{TiO}_{2}\right)$ and $\mathrm{Pd}$ modified $\mathrm{TiO}_{2}\left(\mathrm{Pd} / \mathrm{TiO}_{2}\right)$ were prepared using the same procedure, while without the addition of corresponding precursor. To study the effect of $\mathrm{Cl}$ ions, $\mathrm{PdSO}_{4}$ and $\mathrm{Ni}_{(}\left(\mathrm{NO}_{3}\right)_{2}$ were also used as the precursors, for which the photocatalysts were prepared with the same protocol. Unless stated otherwise, the nominal molar ratio of $\mathrm{Pd}^{2+}$ to $\mathrm{Ti}^{4+}$ is fixed at $1.5 \%$ in the precursor and the one for $\mathrm{Ni}^{2+}$ to $\mathrm{Ti}^{4+}$ is $15 \%$. For comparison, other molar ratio was also used for both $\mathrm{Pd}^{2+}$ to $\mathrm{Ti}^{4+}$ (such as $0.3 \%, 1.0 \%$, and $1.3 \%$ ) and $\mathrm{Ni}^{2+}$ to $\mathrm{Ti}^{4+}$ (such as $5 \%, 10 \%$, and $20 \%$ ).

Characterization. The XRD patterns were acquired using a Rigaku D/max $2500 \mathrm{X}$ ray diffraction spectrometer $(\mathrm{Cu} \mathrm{K} \alpha, \lambda=1.54056 \AA)$. The average crystallite size was calculated according to the Scherrer formula $(D=\mathrm{k} \lambda / B \cos \theta)$. XPS measurements were carried out by using a Thermo ESCALAB 250 spectrometer with an $\mathrm{Al} \mathrm{K \alpha}$ monochromator source and all the binding energies were calibrated to the adventitious C1s peak at $284.8 \mathrm{eV}$. The specific surface area of the obtained catalysts were determined by Brunauer-Emmett-Teller (BET) analysis (Micromeritics, tristar II 3020). Diffuse reflectance UV-visible (UV-vis) absorption spectra were recorded on a UV-vis spectrometer (U-4100, Hitachi). The surface photovoltage spectroscopy (SPS) measurements were performed with a solid sandwich structure via a homemade system using a light source-monochromator lock-in detection technique.

Calculation. All DFT calculations were performed using the DMol3 package $\mathrm{e}^{36,37}$. The generalized gradient approximation (GGA) for the exchange-correlation potential prescribed by Perdew-Burke-Ernzerhof (PBE) and an all-electron double numerical basis set (DND) with polarization functions are used in spin-unrestricted density- functional-theory (DFT) based calculations ${ }^{38}$. For Pd atom, the relativistic effects were also considered. Geometry optimization was performed without symmetry constraint using a convergence criterion of $1.0 \times 10^{-5}$ Hartree on the maximum energy gradient and $0.005 \AA$ on the maximum displacement for each atom. Selfconsistent field (SCF) electronic structure calculations were carried out with a convergence criterion of $1.0 \times 10^{-6}$ Hartree on the total energy.

Photocatalysis. The photocatalytic activity of all photocatalysts were determined by visible-light photodegradation of 4 -XP solution $\left(5 \times 10^{-5} \mathrm{~mol} \mathrm{~L}^{-1}, 40 \mathrm{~mL}\right)$ with a sunlamp (Philips HPA 400/30S, Belgium) and a cutoff filter for the removal of UV light. The reactor was perpendicular to the light beam and located $10 \mathrm{~cm}$ away from the light source. All the suspensions were magnetic stirred at $(25 \pm 2)^{\circ} \mathrm{C}$ in the dark for $30 \mathrm{~min}$ to reach adsorption equilibrium before photocatalysis, and oxygen gas was continuously bubbled through the suspension at a flux of $5 \mathrm{~mL} \mathrm{~min}^{-1}$. The change in concentration of 4-ClP was monitored by a UV-visible spectrometer (UV-1061PC, SHIMADZU) using 4-aminoantipyrine as the chromogenic reagent, while the degradation of 4-FP, 4-BrP and 4-IP was monitored directly by the spectrometer. The reproducibility of the photocatalytic degradation was evaluated by repeating experiments at least three times with different batches of photocatalysts prepared by the same procedure.

1. Linsebigler, A. L., Lu, G. \& Yates Jr, J. T. Photocatalysis on $\mathrm{TiO}_{2}$ surfaces principles, mechanisms, and selected results. Chem. Rev. 95, 735-758 (1995).

2. Fujishima, A., Zhang, X. \& Tryk, D. A. $\mathrm{TiO}_{2}$ photocatalysis and related surface phenomena. Surf. Sci. Rep. 63, 515-582 (2008).

3. Zou, Z. G., Ye, J. H., Sayama, K. \& Arakawa, H. Direct splitting of water under visible light irradiation with an oxide semiconductor photocatalyst. Nature 414, 625-627 (2001).

4. Asahi, R., Morikawa, T., Ohwaki, T., Aoki, K. \& Taga, Y. Visible-light photocatalysis in nitrogen-doped titanium oxides. Science 293, 269-271 (2001).

5. Yang, H. G. et al. Anatase $\mathrm{TiO}_{2}$ single crystals with a large percentage of reactive facets. Nature 453, 638-641 (2008).

6. Chen, X., Liu, L., Peter, Y. Y. \& Mao, S. S. Increasing solar absorption for photocatalysis with black hydrogenated titanium dioxide nanocrystals. Science 331, 746-750 (2011).

7. Satoh, N., Nakashima, T., Kamikura, K. \& Yamamoto, K. Quantum size effect in $\mathrm{TiO}_{2}$ nanoparticles prepared by finely controlled metal assembly on dendrimer templates. Nat. Nanotechnol. 3, 106-111 (2008).

8. Tsukamoto, D. et al. Gold nanoparticles located at the interface of anatase/rutile $\mathrm{TiO}_{2}$ particles as active plasmonic photocatalysts for aerobic oxidation. J. Am. Chem. Soc. 134, 6309-6315 (2012).

9. Liu, G. et al. Nanosized anatase $\mathrm{TiO}_{2}$ single crystals for enhanced photocatalytic activity. Chem. Commun. 46, 755-757 (2010).

10. Wang, E. et al. Improved visible-light photocatalytic activity of titania activated by nitrogen and indium modification. J. Mater. Chem. 22, 14443-14449 (2012).

11. Cao, Y., He, T., Chen, Y. \& Cao, Y. Fabrication of rutile $\mathrm{TiO}_{2}-\mathrm{Sn} /$ anatase $\mathrm{TiO}_{2}-\mathrm{N}$ heterostructure and its application in visible-light photocatalysis. J. Phys. Chem. C 114, 3627-3633 (2010).

12. Chen, X. \& Mao, S. S. Titanium dioxide nanomaterials: synthesis, properties, modifications, and applications. Chem. Rev. 107, 2891-2959 (2007).

13. Yang, M. Q., Zhang, N., Pagliaro, M. \& Xu, Y. J. Artificial photosynthesis over graphene-semiconductor composites. Are we getting better? Chem. Soc. Rev. 43, 8240-8254 (2014).

14. Zhang, N., Zhang, Y. H. \& Xu, Y. J. Recent progress on graphene-based photocatalysts: current status and future perspectives. Nanoscale 4, 5792-5813 (2012).

15. Zhang, Y. H., Tang, Z. R. Fu, X. Z. \& Xu, Y. J. $\mathrm{TiO}_{2}-$ graphene nanocomposites for gas-phase photocatalytic degradation of volatile aromatic pollutant: Is $\mathrm{TiO}_{2}$ - graphene truly different from other $\mathrm{TiO}_{2}$ - carbon composite materials? ACS Nano 4, 7303-7314 (2010).

16. Yang, M. Q. \& Xu, Y. J. Selective photoredox using graphene-based composite photocatalysts. Phys. Chem. Chem. Phys. 15, 19102-19118 (2013).

17. Han, C., Yang, M. Q., Weng, B., \& Xu, Y. J. Improving the photocatalytic activity and anti-photocorrosion of semiconductor $\mathrm{ZnO}$ by coupling with versatile carbon. Phys. Chem. Chem. Phys. 16, 16891-16903 (2014).

18. Weng, B., Liu, S. Q., Tang, Z. R. \& Xu, Y. J. One-dimensional nanostructure based materials for versatile photocatalytic applications. RSC Adv. 4, 12685-12700 (2014).

19. Jana, R., Pathak, T. P. \& Sigman, M. S. Advances in transition metal (Pd, Ni, Fe)catalyzed cross-coupling reactions using alkyl-organometallics as reaction partners. Chem. Rev. 111, 1417-14923 (2011).

20. Molnár, Á. Efficient, selective, and recyclable palladium catalysts in carbon-carbon coupling reactions. Chem. Rev. 111, 2251-2320 (2011).

21. Yin, L. X. \& Liebscher, J. Carbon-carbon coupling reactions catalyzed by heterogeneous palladium catalysts. Chem. Rev. 107, 133-173 (2007).

22. Miyaura, N. \& Suzuki, A. Palladiium-catalyzed cross-coupling reactions of organoboron compounds. Chem. Rev. 95, 2457-2483 (1995).

23. Panpranot, J., Kontapakdee, K. \& Praserthdam, P. Effect of $\mathrm{TiO}_{2}$ crystalline phase composition on the physicochemical and catalytic properties of $\mathrm{Pd} / \mathrm{TiO}_{2}$ in selective acetylene hydrogenation. J. Phys. Chem. B 110, 8019-8024 (2006). 
24. Yang, Y. Z., Chang, C. H. \& idriss, H. Photocatalytic production of hydrogen from ethanol over $\mathrm{M} / \mathrm{TiO}_{2}$ catalysts $(\mathrm{M}=\mathrm{Pd}$, Pt or Rh). Appl. Catal. B 67, 217-222 (2006).

25. Mitome, J. Karakas, G., Bryan, K. A. \& Ozkan, U. S. Effect of $\mathrm{H}_{2} \mathrm{O}$ and $\mathrm{SO}_{2}$ on the activity of $\mathrm{Pd} / \mathrm{TiO}_{2}$ catalysts in catalytic reduction of $\mathrm{NO}$ with methane in the presence of oxygen. Catal. Today 42, 3-11 (1998).

26. Kuvarega, A. T., Krause, R. W. M. \& Mamba, B. B. Nitrogen/palladium-codoped $\mathrm{TiO}_{2}$ for efficient visible light photocatalytic dye degradation. J. Phys. Chem. C 115, 22110-22120 (2011).

27. Bowker, M. etc. Catalysis at the metal-support interface: exemplified by the photocatalytic reforming of methanol on $\mathrm{Pd} / \mathrm{TiO}_{2}$. J. Catal. 217, 427-433 (2003).

28. Li, Q., Li, W., Wu, P. G., Xie, R. C. \& Shang, J. K. Palladium oxide nanoparticles on nitrogen-doped titanium oxide: accelerated photocatalytic disinfection and postillumination catalytic "memory" Adv. Mater. 20, 3717-3723 (2008).

29. Mousty-Desbuquoit, C., Riga, J. \& Verbist, J. J. Solid state effects in the electronic structure of $\mathrm{TiCl}_{4}$ studied by XPS. J. Chem. Phys. 79, 26-32 (1983).

30. Zhu, J., Zheng, W., He, B., Zhang, J. \& Anpo, M. Characterization of Fe-TiO photocatalysts synthesized by hydrothermal method and their photocatalytic reactivity for photodegradation of XRG dye diluted in water. J. Mol. Catal. A 216, 35-43 (2004).

31. Wang, E., Yang, W. \& Cao, Y. Unique surface chemical species on indium doped $\mathrm{TiO}_{2}$ and their effect on the visible light photocatalytic activity. J. Phys. Chem. C 113, 20912-20917 (2009).

32. Leinen, D., Fernandez, A., Espinos, J. \& González-Elipe, A. XPS and ISS study of $\mathrm{NiTiO}_{3}$ and $\mathrm{PbTiO}_{3}$ subjected to low-energy ion bombardment. I. Influence of the type of ion $\left(\mathrm{Ar}^{+}\right.$and $\left.\mathrm{O}^{2+}\right)$. Surface Interface Anal. 20, 941-948 (1993).

33. Theurich, J., Lindner, M. \& Bahnemann, D. W. Photocatalytic degradation of 4chlorophenol in aerated aqueous titanium dioxide suspensions: A kinetic and mechanistic study. Langmuir 12, 6368-6376 (1996).

34. Li, X., Cubbage, J. W. \& Jenks, W. S. Photocatalytic degradation of 4chlorophenol. 2. The 4-chlorocatechol pathway. J. Org. Chem. 64, 8525-8536 (1999).

35. Lipcynska-Kochany, E., Kochany, J. \& Bolton, J. R. Electron paramagnetic resonance spin trapping detection of short-lived radical intermediates in the direct photolysis of 4-chlorophenol in aerated aqueous solution. J. Photochem. Photobiol. A 62, 229-240 (1991).
36. Delley, B. An all-electron numerical method for solving the local density functional for polyatomic molecules. J. Chem. Phys. 92, 508-517 (1990).

37. Delley, B. From molecules to solids with the Dmol3 approach. J. Chem. Phys. 113, 7756-7764 (2000).

38. Perdew, J. P., Burke, K. \& Ernzerhof, M. Generalized gradient approximation made simple. Phys. Rev. Lett. 77, 3865-3868 (1996).

\section{Acknowledgments}

This work was supported by the National Natural Science Foundation of China (21173121 and 51372120), the Hundred-Talent Program of Chinese Academy of Sciences, and National Research Fund for Fundamental Key Projects No. 973 (2011CB933200).

\section{Author contributions}

Y.L.Y. is the major implementer of the research. Y.J.Y. and L.M.G. took part in photocatalysis measurements. L.J.G. did the theoretical calculation. Y.T. participated in the sample preparation. T.H. and Y.A.C. supervised the research and co-wrote the paper. All authors contributed to the discussion and provided feedback on the manuscript.

\section{Additional information}

Supplementary information accompanies this paper at http://www.nature.com/ scientificreports

Competing financial interests: The authors declare no competing financial interests. How to cite this article: Yu, Y. et al. Efficient visible-light photocatalytic degradation system assisted by conventional Pd catalysis. Sci. Rep. 5, 9561; DOI:10.1038/srep09561 (2015).

This work is licensed under a Creative Commons Attribution 4.0 International License. The images or other third party material in this article are included in the article's Creative Commons license, unless indicated otherwise in the credit line; if the material is not included under the Creative Commons license, users will need to obtain permission from the license holder in order to reproduce the material. To view a copy of this license, visit http://creativecommons.org/licenses/by/4.0/ 


\section{SCIENTIFIC REP RTS}

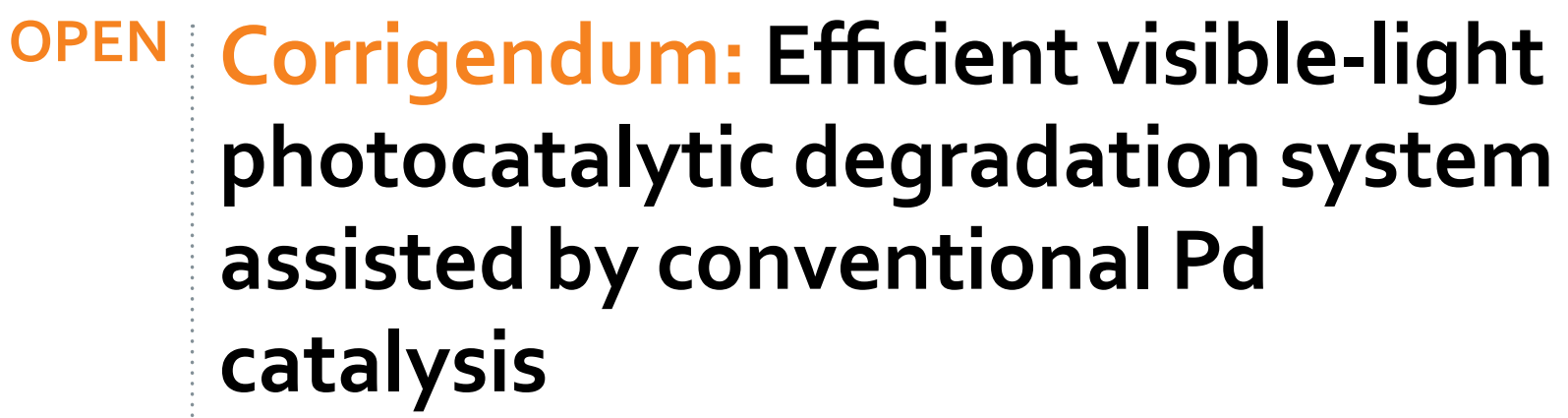

Yanlong Yu, Tao He, Lingju Guo, Yajun Yang, Limei Guo, Yue Tang \& Yaan Cao

Correction to: Scientific Reports https://doi.org/10.1038/srep09561; published online 31 March 2015; updated 14 May 2018

This Article contains an error. The Authors stated that the cell volume and lattice parameters were derived using Scherrer's formula. These parameters were actually calculated using Bragg's law.

In the Results section,

"The cell volume and lattice parameters can be derived from the diffraction peaks corresponding to crystal planes (101) and (200) in the XRD patterns using Scherrer's formula, for which of $\mathrm{Ni}^{-} \mathrm{TiO}_{2}$ are larger than those of pure $\mathrm{TiO}_{2}$ (Table 1)."

should read:

"The cell volume and lattice parameters can be derived from the diffraction peaks corresponding to crystal planes (101) and (200) in the XRD patterns using Bragg's law, for which of $\mathrm{Ni}^{-\mathrm{TiO}_{2}}$ are larger than those of pure $\mathrm{TiO}_{2}$ (Table 1)."

This change does not affect the conclusions of the article. The authors apologize for the error.

(c) (i) This work is licensed under a Creative Commons Attribution 4.0 International License. The images or other third party material in this article are included in the article's Creative Commons license, unless indicated otherwise in the credit line; if the material is not included under the Creative Commons license, users will need to obtain permission from the license holder to reproduce the material. To view a copy of this license, visit http://creativecommons.org/licenses/by/4.0/

(c) The Author(s) 2018 